\title{
Dinâmica de Ocupação do Cerrado Nordestino pela Agricultura: 1990 e $2012^{1}$
}

\author{
Junior Ruiz Garcia² e Antônio Márcio Buainain³
}

Resumo: O setor agropecuário tem sido um importante vetor do desenvolvimento regional e da própria economia brasileira. Neste sentido, o uso de indicadores e métodos para a identificação das fontes de crescimento da produção agrícola pode subsidiar a concepção de políticas mais adequadas para a gestão do uso das terras em fronteiras agrícolas, assim como orientar os investimentos em infraestrutura. A partir dos anos 1990 uma nova fronteira agrícola, apoiada em modernas bases de produção, está sendo aberta no País, no território conhecido como Cerrado Nordestino. Neste contexto, o objetivo principal é analisar a dinâmica de ocupação do Cerrado Nordestino pelas culturas temporárias entre 1990 e 2012. A análise foi realizada com auxílio do Modelo Shift-share, mas na escala municipal, o que permitiu a espacialização dos resultados e a identificação de áreas mais dinâmicas. A soja e o milho têm comandado a ocupação da fronteira agrícola.

Palavras-chave: Produção agrícola; Agronegócio; Shift-share; Sistema de Informações Geográficas (SIG's); Fronteira agrícola.

Abstract: The agricultural sector has been an important driver for regional development in Brazil and the Brazilian economy as a whole. In this sense, the use of indicators and methods to identify the sources of growth of crop production in the Northeastern Cerrado region can support the design of policies to manage the use and occupation of land in agricultural areas, as well as guide investment in infrastructure, for example. From the 1990s onwards, a new agricultural frontier based on capital intense production systems is being opened in Brazil, the territory known as Cerrado Nordestino. In this context, the aim of this paper is to identify and analyze, based on the Shift-share Model, some of the sources of growth in temporary crop production in Cerrado Nordestino from 1990 to 2012, which are leading the occupation of the territory. The results were performed at the municipal

1. Data de submissão: 16 de novembro de 2015. Data de aceite: 9 de março de 2016.

2. Departamento de Economia, Universidade Federal do Paraná (UFPR), Curitiba, Paraná, Brasil. Bolsista de Produtividade em Pesquisa do CNPq, nível 2, CA EA, Administração, Contabilidade e Economia. E-mail: jrgarcia1989@gmail.com

3. Instituto de Economia, Universidade Estadual de Campinas (Unicamp), Pesquisador do Instituto Nacional de Ciência e Tecnologia em Políticas Públicas, Estratégia e Desenvolvimento (INCT/ PPED). E-mail: buainain@gmail.com 
scale, which allowed the spatial distribution of crops and the identification of the most dynamic areas. Soybean and corn have driven the occupation of agricultural frontier.

Key-words: Crop production; Agribusiness; Shift-share; Geographic Information System (GIS); Agricultural frontier.

Classificação JEL: Q10, Q15, Q19.

\section{Introdução}

A agricultura tem sido um importante vetor do desenvolvimento regional e da própria economia brasileira (Buainain e Garcia, 2015). Tradicional fonte de mão de obra, insumos, capital e divisas para as atividades urbano-industriais no período mais recente, a agricultura tem desempenhado papel central no controle da inflação, na garantia da segurança alimentar, na geração direta de ocupação no meio rural e indireta no meio urbano e também na integração socioeconômica do território nacional. Essa dinâmica está relacionada aos resultados proporcionados pela "modernização conservadora" (GRAZIANO DA SILVA, 1996), os quais incluem a forte integração entre a agricultura e os setores não agrícolas, a partir da incorporação de novas tecnologias no manejo dos cultivos, distribuição e processamento dos produtos, dando origem ao agronegócio e aos complexos agroindustriais (KAGEYAMA, 1987; MÜLLER, 1989; ROSS e SANCHES, 2001; ANDRADES e GANIMI, 2007; BUAINAIN et al., 2014).

Em que pese a imprecisão, o dinamismo do agronegócio brasileiro contemporâneo está, em grande medida, identificado com o avanço da agricultura para as novas áreas de fronteira, particularmente no Centro-Oeste (MUELLER, 1990;
VIEIRA JR. et al., 2006; BUAINAIN et al., 2014), e mais recentemente para a região Nordeste do País, tradicionalmente associado à monocultura canavieira de baixa produtividade e à agropecuária extensiva do semiárido. A "domesticação" do Cerrado, proporcionada pelas novas técnicas de produção desenvolvidas no âmbito das instituições públicas de pesquisa, dentre as quais se destaca a Embrapa (Empresa Brasileira de Pesquisa Agropecuária) (MIRANDA e GOMES, 2011), permitiu a obtenção de elevados ganhos de produtividade (GASQUES et al., 2004, 2007, 2011), particularmente em regiões antes consideradas inaptas à agricultura (IBGE, 2015c). Contudo, os resultados não se refletiram apenas no aumento da produtividade. A nova organização produtiva também permitiu que a agricultura se tornasse um importante vetor de expansão da economia local e de desenvolvimento, ainda que com intensidade e impactos socioeconômicos diferenciados entre os vários "polos" e novas fronteiras que se abriram a partir da década de 1970 (TEIXEIRA, 2005; LIMA et al., 2006; BUAINAIN et al., 2014).

Apesar do inquestionável sucesso e da importância econômica e social desta "nova" agricultura, a dinâmica e as formas de ocupação das fronteiras não têm sido imunes a críticas e controvérsias, as quais envolvem impactos ambientais, econômicos, distributivos e políticos. Muitos autores 
(CANUTO, 2004; CAMACHO, 2009; SILVA, 2015) enxergam a fronteira como o espaço do latifúndio metamorfoseado, modernizado tecnicamente, mas destruidor do ambiente natural, concentrador da riqueza, produtor de pobreza e exclusão dos pequenos produtores. Outros (ver a coleção de ensaios sobre o assunto em BUAINAIN et al., 2014), mesmo reconhecendo os inúmeros problemas e as distorções, consideram virtuoso este novo padrão de acumulação instalado na agricultura, tanto do ponto de vista econômico como social, político e ambiental.

Este debate tem focalizado a atenção nas regiões da floresta Amazônica e no Centro-Oeste, negligenciando os processos de ocupação e reocupação que vêm ocorrendo desde a década de 1990, por exemplo, nos Cerrados Nordestinos - $\mathrm{CN}$, território caracterizado por fortes restrições ecológicas, sociais e econômicas (VIDAL e EVANGELISTA, 2012; SUASSUNA, 2013; BUAINAIN e GARCIA, 2015). Entretanto, em muitas regiões do País o dinamismo da agricultura não foi suficiente para transbordar o âmbito setorial e dar origem a polos econômicos fora da agricultura. Assim, quando o setor agrícola entra em crise, a região perde seu dinamismo e capacidade de manter o emprego, ocupação e a renda. É neste contexto que se insere a presente reflexão, que procura responder às seguintes questões: Como tem sido a dinâmica de ocupação pela agricultura no CN? Qual tem sido o padrão espacial dessa ocupação? Quais são as principais culturas agrícolas que têm comandado essa ocupação? Que desdobramentos se podem esperar em termos de propulsão do desenvolvimento regional?

A ocupação territorial é determinada e "movida" por múltiplos fatores econômicos e populacionais. No próprio meio rural as forças se dividem entre a dinâmica agrícola - lavouras temporárias e permanentes -, pecuária, silvicultura e grandes obras de engenharia, só para citar alguns dos fatores mais importantes. Diante deste espectro, a análise da dinâmica de ocupação examinada pela evolução das lavouras tem- porárias entre 1990 e 2012 no CN é sem dúvida modesta, mas ainda assim válida, uma vez que estas lavouras têm sido as portadoras iniciais das mudanças estruturais registradas na agricultura e na própria economia do Centro-Oeste. Ademais, as lavouras temporárias ocupam $97,3 \%$ do total de 4,7 milhões de hectares com lavouras nos CN em 2012 (IBGE, 2015c). Já a escolha do período está relacionada ao início da ocupação agrícola na região e a própria consolidação da nova fronteira agrícola. A avaliação foi realizada com auxílio do modelo Shift-share, aplicado à escala municipal, e não a partir de médias estaduais que escondem particularidades e diferenciações importantes no processo de ocupação econômica do território. $\mathrm{O}$ uso da escala municipal permite a espacialização dos resultados - integrada ao uso das geotecnologias - e a melhor identificação das áreas mais dinâmicas no $\mathrm{CN}$, ou seja, sua heterogeneidade. A aplicação do modelo Shift-share se justifica por se tratar de uma análise exploratória do processo de ocupação dessa nova fronteira agrícola no País. Ademais, esse modelo permite avaliar a expansão da produção agrícola a partir de sua decomposição em efeitos área plantada, rendimento, estrutura produtiva e localização geográfica. Apesar de tradicional, esse modelo ainda tem sido muito usado e validado por autores relevantes (CURTIS, 1972; HOMMA, 1981; IGREJA et al., 1982; SENF, 1988; YOKOYAMA, IGREJA e NEVES, 1990; CARVALHO et al., 1994; SCHEER e ROCHA, 2005; FELIPE e MAXIMIANO, 2008; FELIPE et al., 2010; HERATH, GEBREMEDHIN e MAUMBE, 2011; BASTOS e GOMES, 2011; PADRÃO et al., 2012; TEIXEIRA e MENDES, 2013; DIAS et al., 2013; FEIX e ZANIN, 2013; BITTENCOURT e GOMES, 2014; SOUZA e WANDER, 2014; SANTOS e ARAÚJO, 2014).

O trabalho está organizado em três seções, além desta introdução. A segunda apresenta a área de estudo e a metodologia utilizada no estudo. Na terceira seção, são apresentados e discutidos os principais resultados. Por fim, na última, encontram-se as considerações finais. 


\section{Materiais, literatura e métodos}

\subsection{O modelo Shift-share e seu uso na análise agrícola}

O modelo Shift-share tem sido utilizado para identificar e avaliar os componentes de variação (positiva ou negativa) do crescimento de uma região em relação ao seu espaço de referência (DUNN, 1960; BROWN, 1969, 1971; CURTIS, 1972; ESTEBAN-MARQUILLAS, 1972; HERZOG e OLSEN, 1977; BARFF e KNIGHT III, 1988; SENF, 1988; HERATH, GEBREMEDHIN e MAUMBE, 2011). Esse modelo também tem sido aplicado para analisar os componentes de variação de determinada variável, tais como o número de pessoas empregadas, a produção agrícola, o produto econômico de uma atividade, a renda, dentre outras variáveis, independente da unidade de medida. A facilidade de aplicação e o poder de revelar as contribuições de fatores específicos para o comportamento da variável estudada explicam a popularidade do modelo, cuja simplicidade não o debilita frente a outros métodos mais complexos e as suas limitações.

As principais fontes de variação identificadas pelo modelo Shift-share geral são: efeito do crescimento do espaço de referência (componente nacional); efeito da estrutura produtiva (componente estrutural ou setorial); efeitos específicos da região, como fatores ou vantagens locacionais (componente regional) (DUNN, 1960; BROWN, 1969; CURTIS, 1972; ESTEBAN-MARQUILLAS, 1972; HERZOG e OLSEN, 1977; BARFF e KNIGHT III, 1988; SENF, 1988; HERATH, GEBREMEDHIN e MAUMBE, 2011). Cabe destacar que o uso do modelo Shift-share, em sua versão adaptada para o setor agrícola, segundo Igreja et al. (1982, p. 1), permite a identificação dos principais componentes da produção agrícola, auxiliando na concepção de políticas de crescimento econômico mais adequadas para a agricultura, tanto em caráter global como regional. Esses indicadores têm aportado resultados valiosos para detectar mudanças em importantes variáveis, tais como a produtividade dos recursos econômicos ou fatores de produção direta ou indiretamente envolvidos na produção agrícola.

Um conjunto de estudos tem usado o modelo Shift-share na análise agrícola (CURTIS, 1972; HOMMA, 1981; IGREJA et al., 1982; SENF, 1988; YOKOYAMA, IGREJA e NEVES, 1990; CARVALHO et al., 1994; SCHEER e ROCHA, 2005; FELIPE e MAXIMIANO, 2008; HERATH, GEBREMEDHIN e MAUMBE, 2011). Os resultados da aplicação do modelo Shift-Share são interessantes e podem de fato orientar a tomada de decisão, como sugerem Igreja et al. (1982), uma vez que mostram como as fontes de variação da produção agrícola se modificam ao longo do tempo, e como elas variam em função das especificidades regionais ou da localização geográfica. Assim, o componente espacial tem um importante papel na análise, ao identificar as vantagens locacionais na produção (PADRÃO et al., 2012).

A aplicação do modelo Shift-share neste estudo contempla a análise de quatro efeitos (IGREJA et al., 1982; SCHEER e ROCHA, 2005; FELIPE e MAXIMIANO, 2008): efeito área (EA); efeito rendimento (ER); efeito localização geográfica (ELG) e efeito da estrutura produtiva (EEP). A avaliação simultânea de todos os efeitos somente é possível para o espaço de referência, neste estudo o $\mathrm{CN}$, seja para uma cultura agrícola específica seja para um conjunto de culturas agrícolas. Por sua vez, a análise por município permite avaliar os efeitos área, rendimento e estrutura produtiva, além de identificar as diferenças nas regiões estudadas.

$\mathrm{O}$ efeito área (EA) revela a parcela da variação na produção agrícola resultante de mudanças ocorridas apenas na área plantada. A estimativa do efeito área considera constante o rendimento (t/ha.), a localização geográfica e a estrutura produtiva (IGREJA et al., 1982; SCHEER e ROCHA, 2005; FELIPE e MAXIMIANO, 2008). Isto significa que qualquer variação na quantidade produzida se deve à variação da área plantada, que representa o meio mais tradicional de ajustar a produção agrícola aos demais condicionantes. No Brasil, até o final dos anos 1960, a expansão da agricultura deveu-se, fundamentalmente, à ocupação da fronteira agrícola, via aumento da área 
cultivada, caracterizado como padrão de crescimento extensivo (SILVA DIAS e AMARAL, 2001; GRAZIANO DA SILVA, 2002; VEIGA, 2004).

$\mathrm{O}$ efeito rendimento (ER) identifica a contribuição da produtividade ou rendimento na produção agrícola, mantendo-se constante a área plantada, a localização geográfica e a estrutura produtiva (IGREJA et al., 1982; SCHEER e ROCHA, 2005; FELIPE e MAXIMIANO, 2008). $\mathrm{O}$ efeito rendimento pode ser considerado como proxy da introjeção tecnológica na produção agrícola, ou seja, da intensificação de uso de meios de produção intensivos em tecnologia. Vale ressaltar que, no período recente, a inovação tecnológica pode ser considerada como o principal vetor de crescimento da produção agrícola no Brasil conforme apontam os estudos de Gasques et al. (2004, 2007, 2011) e Fornazier e Vieira Filho (2013).

O efeito localização geográfica (ELG) avalia a parcela da variação na produção agrícola associada às vantagens locacionais em relação à dinâmica verificada no espaço de referência (IGREJA et al., 1982; FELIPE e MAXIMIANO, 2008). Segundo Igreja et al. (1982),

as vantagens locacionais de uma cultura se traduzem num efeito positivo quando a expansão da área cultivada em algumas regiões for suficiente para contrabalançar a estabilidade e/ou retração nas demais regiões, e for acompanhada de produtividades médias superiores (p. 6).

Os autores destacam ainda que, mesmo que ocorra uma redução da área plantada, o efeito das vantagens locacionais ainda pode ser positivo caso a região tenha mantido ganhos relativos na produtividade. Este efeito é importante no caso brasileiro, cuja fronteira agrícola nunca se fechou e está sempre em movimento, com redefinição do uso do solo entre diferentes localizações geográficas, como é o caso do CN. Ainda, é importante considerar que estes movimentos são em geral acompanhados por mudanças tecnológicas e por transformações na estrutura produtiva, o que pode embaralhar os efeitos área, rendimento, localização e estrutura produtiva.
O efeito estrutura produtiva (EEP) mensura as alterações no conjunto da produção levando em conta a área relativa total plantada com as diferentes culturas, a partir do suposto de que a área plantada total e o rendimento permaneçam constantes (IGREJA et al., 1982; SCHEER e ROCHA, 2005; FELIPE e MAXIMIANO, 2008). Segundo Igreja et al. (1982), a mudança na composição da estrutura produtiva permite que a produção sofra uma expansão em função da substituição de uma cultura com menor produtividade por outra com maior produtividade. Trata-se de um efeito relevante para o caso brasileiro recente, caracterizado pela "fronteira em movimento", com profundas mudanças na estrutura produtiva da agricultura. Ainda assim, esse efeito tem sido subestimado, e parte dos resultados decorrentes das alterações da composição das lavouras tem sido atribuída, diretamente, à inovação tecnológica.

Os modelos matemáticos usados no estudo constam no material suplementar. Contudo, vale destacar que os resultados são apresentados em mapas na escala espacial do município, com o auxílio das geotecnologias, Sistema de Informação Geográfica (SIG), permitindo a verificação da variação dos efeitos estimados a partir do modelo Shift-share no espaço e no tempo. A análise espacial dos componentes de variação da expansão da produção das lavouras temporárias por município do $\mathrm{CN}$ pode auxiliar na identificação de regiões que apresentam maior dinamismo em determinado componente. Os resultados dos efeitos foram qualificados em cinco graus de contribuição na constituição do efeito total (expansão), obtidos a partir da razão entre o efeito analisado $\left(E_{X}\right)$ - em que $X$ pode representar o efeito área, o efeito rendimento ou o efeito estrutura produtiva - e o efeito total $\left(E_{T}\right)$, como segue:

Grau de contribuição $=\frac{E_{X}}{E_{T}}$

Graus de contribuição, interpretação:

- Alto positivo: indica que o efeito analisado $\left(E_{X}\right)$ foi positivo e superior ao efeito total $\left(E_{T}\right)$, ou seja, $E_{X}>1$; 
- Baixo positivo: indica que o efeito analisado $\left(E_{\mathrm{X}}\right)$ foi positivo, mas o resultado está no intervalo maior que zero e inferior ou igual ao efeito total $\left(E_{T}\right), 0<E_{\mathrm{X}} \leq 1$;

- Nulo: indica que o efeito analisado $\left(E_{\mathrm{x}}\right)$ foi igual a zero, seja porque não houve variação, seja porque não havia ocorrência de produção, $E_{\mathrm{X}}=0$;

- Baixo negativo: indica que o efeito analisado $\left(E_{X}\right)$ foi negativo, mas o resultado está no intervalo menor que zero e inferior ou igual ao efeito total $\left(E_{T}\right), 0>E_{X} \leq-1$;

- Alto negativo: indica que o efeito analisado $\left(E_{X}\right)$ foi negativo, mas superior ao efeito total $\left(E_{T}\right)$, ou seja, $E_{X}<-1$.

Em síntese, a análise espacial dos resultados permite melhor visualização do padrão de expansão das lavouras temporárias do $\mathrm{CN}$, ou seja, sua heterogeneidade, e fornece subsídios mais adequados para a formulação de políticas públicas para o desenvolvimento regional.

\section{2. Área de estudo}

O CN, parcela do Bioma Cerrado, tem área de 645 mil km² (64,5 milhões de hectares) distribuída em quatro estados da região Nordeste, do norte de Minas Gerais ao litoral do Maranhão, inclui 357 municípios, representa 7,6\% do território nacional e 31,7\% do Bioma Cerrado (Figura 1$)^{4}$.

Em 2010, o CN abrigava população de 8,3 milhões de pessoas, $4,3 \%$ da brasileira, densidade demográfica de $12,8 \mathrm{hab} . / \mathrm{km}^{2}$, inferior à nacional (22,4 hab./ $\left.\mathrm{km}^{2}\right)$, população rural de 2,9 milhões e taxa de urbanização de $65 \%$, abaixo da nacional (84\%) (IBGE, 2015b). O Produto Interno Bruto a preços correntes (PIB- $\mathrm{M}_{\mathrm{pm}}$ ) do $\mathrm{CN}$ foi estimado em R \$ 59,6 bilhões em 2010, equivale a 1,6\% do brasileiro e resulta em um PIB per capita de R\$

4. Considera-se que parcela do norte de Minas Gerais deve compor o Cerrado Nordestino $(\mathrm{CN})$ porque esta região apresenta características mais próximas às do Nordeste do que aquelas encontradas no Sudeste. Além disso, esse território envolve a área de atuação do Banco do Nordeste (BNB).
7,2 mil (IBGE, 2015d). Por fim, em 2010, o Valor Adicionado Bruto (VAB) do $\mathrm{CN}$, a preços correntes, tinha a seguinte composição: agropecuária $\mathrm{R} \$ 10$ bilhões $(18,4 \%)$; indústria $\mathrm{R} \$ 9,2$ bilhões (16,9\%) e serviços R\$ 35,3 bilhões (64,7\%) (IBGE, 2015d). O VAB revela a importância econômica do setor agrícola no $\mathrm{CN}$, respondendo por quase $20 \%$ do produto da economia.

\subsection{Fontes dos dados}

Os dados utilizados neste estudo foram obtidos da Pesquisa Agrícola Municipal (PAM), do Instituto Brasileiro de Geografia e Estatística (IBGE), para lavouras temporárias. ${ }^{5} \mathrm{O}$ cultivo de abacaxi foi excluído porque a quantidade produzida e o rendimento médio por hectare estavam em unidades (número de abacaxis), dificultando a agregação direta com a produção e rendimento dos demais produtos. ${ }^{6}$

As variáveis utilizadas no estudo são: área plantada (hectares); rendimento médio por hectare (toneladas/hectare) e quantidade produzida (toneladas). As variáveis foram coletadas na escala municipal a partir do Sistema IBGE de Recuperação Automática (Sidra) para os seguintes períodos: 1990/1991/1992; 1999/2001/2002; 2010/2011/2012. Optou-se por utilizar a média trienal para amenizar os efeitos sazonais típicos de lavouras temporárias. A análise avalia a dinâmica decenal das lavouras temporárias no $\mathrm{CN}$.

5. As lavouras permanentes não foram incluídas neste estudo, porque elas ocupam apenas 120 mil hectares no Cerrado Nordestino (IBGE, 2015c). Desse modo, a expansão da agricultura no $\mathrm{CN}$ tem sido comandada pelas lavouras temporárias. Em relação à pecuária, segundo dados do Censo Agropecuário 2006, a área com pastagens alcançava 10,4 milhões de hectares - pastagens naturais ocupavam 3,5 milhões, pastagens degradadas, 1 milhão e pastagens plantadas em boas condições, 5,9 milhões. Contudo, os dados disponíveis em termos da produção e do período analisado dificultam a compatibilização com as lavouras temporárias. Desse modo, optamos por não incluir a pecuária na análise.

6. A exclusão do cultivo de abacaxi não prejudica a análise, porque essa cultura não se mostrou representativa em termos de área plantada no $\mathrm{CN}$, respondendo por menos de $0,04 \%$ da área plantada total com lavouras temporárias em 2012 (IBGE, 2015c). 
Figura 1. Localização do Cerrado Nordestino

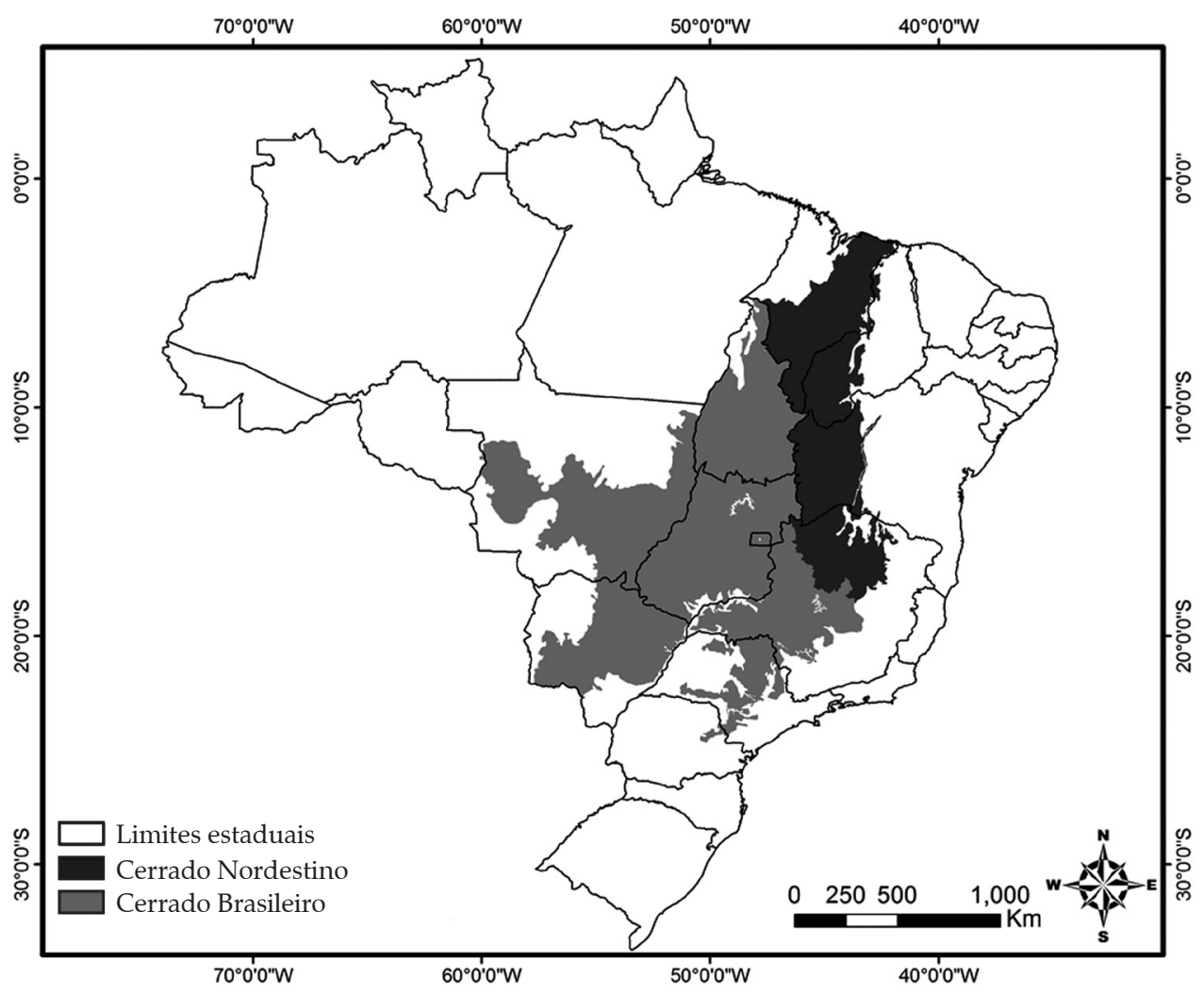

Fonte: Elaborado pelos autores com base em BNB (2015), IBGE (2015a).

\section{Resultados e discussão}

\subsection{Análise Shift-Share}

Uma síntese dos resultados por produto cultivado no $\mathrm{CN}$ é apresentada nas Tabelas 1 e 2 . A análise dos resultados revelou que a quantidade produzida cresceu 119\% entre 1990-1992 e 20102012, saltando de 8,9 milhões de toneladas para 19,5 milhões de toneladas. Esse aumento foi inferior ao registrado pela produção nacional, que no mesmo período cresceu $160 \%$ (IBGE, 2015c). Trata-se de uma primeira constatação muito importante, uma vez que o "senso comum" atribui um dinamismo à região do $\mathrm{CN}$ que não é confirmado pela evolução da produção. Contudo, não se pode negligenciar o fato de se tratar de crescimento da produção agrícola em uma região considerada, até recentemente, inapta ou com fortes restrições ao desenvolvimento da atividade agrícola em função das suas características edafoclimáticas (LOPES, 1984; MIRANDA e GOMES, 2011), e que apesar da disponibilidade de tecnologia que viabilizou a expansão no período recente, ainda se caracteriza por restrições ecológicas, sociais e econômicas. Isto significa que a expansão da produção agrícola no $\mathrm{CN}$ foi possível a partir da modernização dos sistemas produtivos tradicionais. Os produtos agrícolas que mais contribuíram para este desempenho foram a cana-de-açúcar (6,2 milhões de toneladas em 2012), a soja (6 milhões), o milho (3 milhões), a mandioca (1,6 milhão) e o algodão herbáceo (1,4 milhão). Esses resultados revelam certa discrepância entre a imagem que se difundiu do $\mathrm{CN}$, muito mais associada ao cultivo de algodão do que ao cultivo de cana-de-açúcar e mandioca, para mencionar dois produtos tradicionais da agricultura nordestina. 


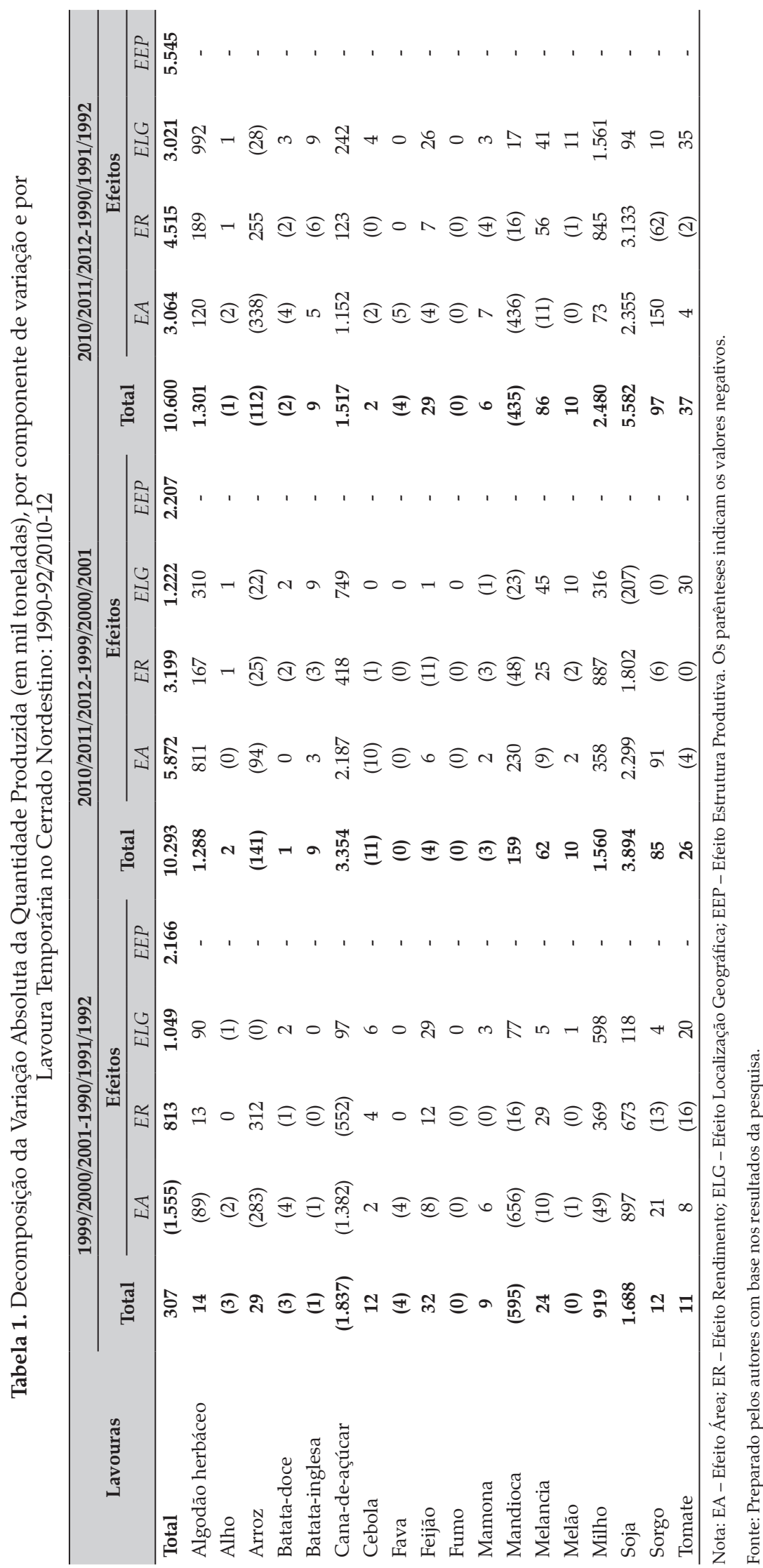




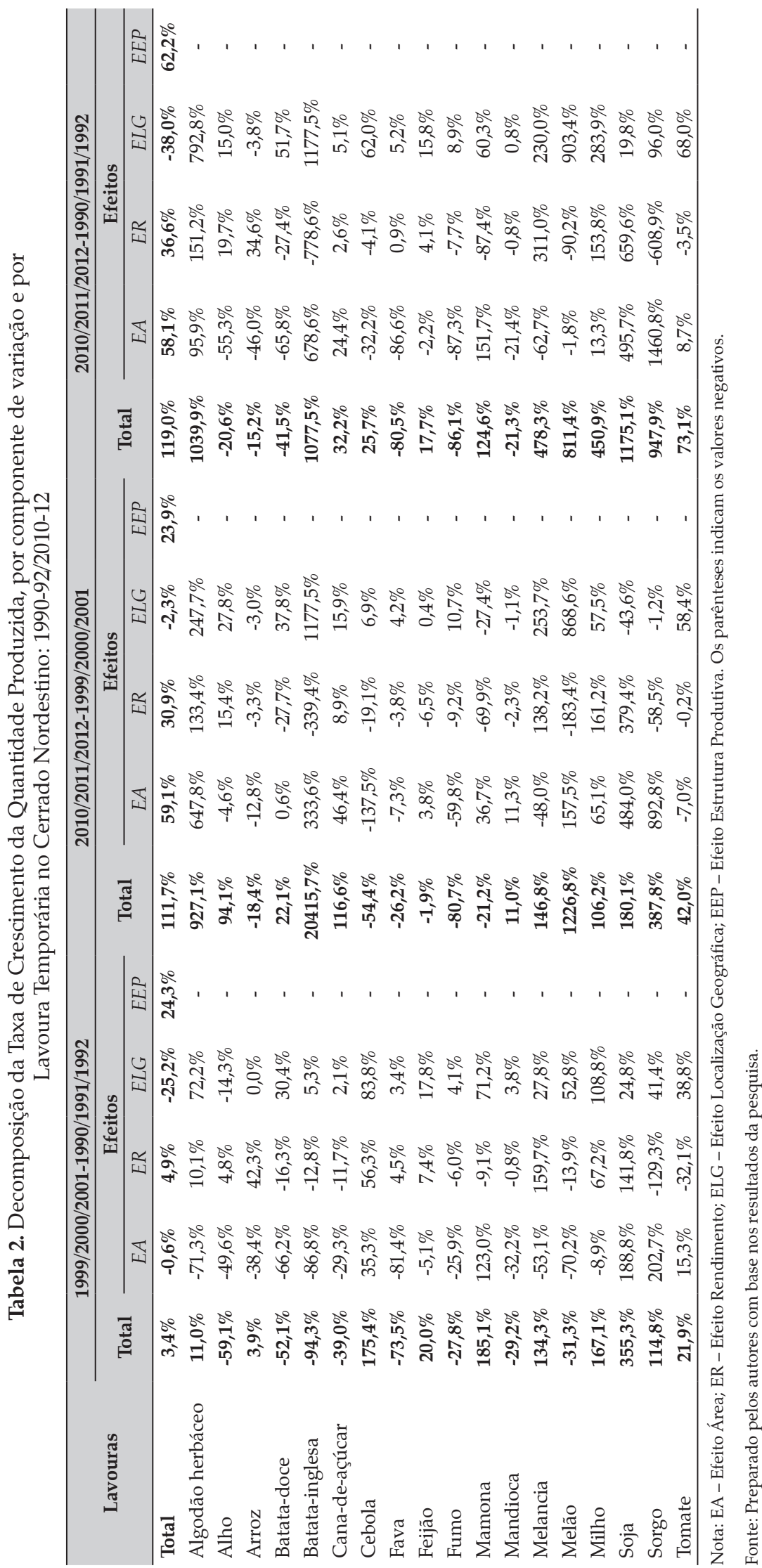


Cabe destacar que a análise da evolução da produção agrícola revelou que a dinâmica de ocupação apresenta dois períodos distintos. O primeiro, na década de 1990, representado pelo período 1990-1992/1999-2001. O segundo, nos anos 2000, representado pelo período 19992001/2010-2012. Esses dois períodos correspondem, grosso modo, a fases e conjunturas distintas da economia nacional e do próprio desempenho da agricultura em geral. Essa segmentação temporal revela que as mudanças na ocupação podem estar associadas ao próprio estágio da economia do $\mathrm{CN}$ e que podem se acelerar e ou arrefecer à medida que a atividade se consolida (devido até mesmo ao efeito estatístico da ampliação da base de cálculo). Além disso, interessa identificar os condicionantes do desempenho no período mais recente, uma vez que, pela experiência nacional e de outros países, nos primeiros anos a ocupação da fronteira se baseia muito mais na ocupação das terras, que se evidencia no efeito área, e posteriormente ao efeito rendimento na medida em que investimentos são realizados a partir da constatação da viabilidade e aptidão local para a cultura $x$ ou $y$.

Em tese e pela experiência histórica de ocupação do Sul e Sudeste do Brasil, a expansão da fronteira, no primeiro período, seria facilitada pela disponibilidade de terras mais baratas, pouco exploradas, com fertilidade natural preservada, e no segundo período dependeria da disponibilidade de capital e das condições de mercado mais favoráveis para a realização dos investimentos. No entanto, esta trajetória e tese não são válidas para o Cerrado, cujas terras não são naturalmente férteis e cuja exploração com lavouras comerciais em maior escala exige investimentos imediatos em correção de solos, fertilização, aquisição de equipamentos e gastos elevados em insumos em geral. A ocupação exige também uma adaptação da tecnologia disponível e aprendizado por parte dos agricultores, feito com base em erros cujos custos são cobertos pelos próprios agricultores - e acertos, sem necessariamente receber o suporte do setor público. Isto significa que a primeira etapa de ocupação é mais difícil do que a segunda. Uma vez evidenciada a viabilidade da exploração da terra pelos pioneiros, novos produtores são atraídos, firmas, serviços etc., dinamizando e levando a um processo de adensamento da economia local.

No primeiro período, que corresponde ao triênio 1999/2000/2001-1990/1991/1992, a expansão das lavouras temporárias foi de apenas 3,4\%, aumento de 307 mil toneladas. Por um lado, o efeito área e o efeito localização geográfica foram negativos, registrando queda de $0,6 \%$ e $25 \%$, respectivamente. Por outro, o efeito rendimento e o efeito estrutura produtiva foram positivos, aumento de $5 \%$ e $24 \%$, respectivamente, o que permitiu o aumento da produção. Essa dinâmica revelou a perda de importância relativa do fator terra na expansão da produção, uma vez que a primeira fase de ocupação tem sido associada à incorporação de novas terras. Os resultados indicam que a ocupação desta região de fronteira agrícola envolveu uma base tecnológica e investimentos mais elevados do que o modelo de ocupação extensivo, baseado quase inteiramente na ocupação de novas áreas e na exploração da fertilidade natural das terras virgens desmantadas para o plantio de lavouras e pastos (BUAINAIN et al., 2014). A ocupação do CN é sustentada, desde os anos 1990, por uma nova composição do produto e pela elevação do nível de rendimento em relação à situação anterior.

Apesar de o aumento da produção ter sido pequeno, a região revelou uma dinâmica interessante. Neste primeiro período, soja e milho assumiram um importante papel na composição e na dinâmica agrícola do $\mathrm{CN}$, revelando seu potencial. No início do período, a produção de soja era de 475 mil toneladas, mas no final já ultrapassava 2,1 milhões, expansão de 355\%. Neste caso, o aumento foi sustentado basicamente pelos efeitos área $(189 \%)$ e rendimento $(142 \%)$ e, em menor grau, pelo efeito localização geográfica (25\%). Observa-se que o aumento da área plantada apresentou a maior contribuição, ou seja, o fator terra foi primordial na expansão da soja. Trata-se de uma constatação que não surpreende, pois estes produtos, principalmente a soja, não 
estavam presentes na agricultura local, de onde deriva que sem a expansão da área cultivada não seria possível que a produção crescesse nos períodos posteriores, mais impulsionadas pela inovação do que pela área. Contudo, o efeito rendimento também apresentou importante contribuição, o que evidencia o papel dos ganhos obtidos com a incorporação tecnológica em uma região que já era de certa forma ocupada e marcada pelo uso extensivo dos recursos naturais. Esse resultado confirma a implantação de um novo padrão produtivo, mais intensivo em capital e tecnologia, reproduzindo o já consolidado nos cerrados do Centro-Oeste. Por sua vez, a produção do milho saltou de 550 mil toneladas para 1,47 milhão, aumento de $167 \%$. O efeito área foi negativo (-9\%), assim, a expansão se deve inteiramente ao efeito localização geográfica $(109 \%)$ e ao efeito rendimento (67\%). Este resultado é explicado pela presença prévia do milho, que já era cultivado em sistemas de consórcio com feijão e outras culturas cultivadas na região em bases produtivas precárias, extensiva e de caráter tradicional. A introdução dos sistemas produtivos mais modernos, a partir dos anos 1990, não precisou ampliar a área cultivada, mas apenas mudar o sistema produtivo até então utilizado, e deslocar a produção para áreas de melhor aptidão agrícola.

Outro resultado interessante verificado é a redução na produção de cana-de-açúcar e de mandioca ainda neste primeiro período, queda de 1,8 milhões de toneladas (-39\%) e de 595 mil toneladas (-29\%), respectivamente. A queda da cana-de-açúcar foi resultado do efeito área $(-29,3 \%)$ e do efeito rendimento $(-11,7 \%)$. No caso da mandioca, a queda também foi resultado do efeito área $(-32,2 \%)$ e, em menor grau, do efeito rendimento $(-0,8 \%)$. Essas culturas foram "doadoras" de área para a expansão da soja e do milho. Outra cultura "doadora" foi o arroz, que registrou efeito área negativo de $38,4 \%$, mas o efeito rendimento foi de $42,3 \%$, contribuindo para a expansão de $4 \%$ na produção. Mesmo registrando queda na área plantada, o arroz apresenta aumento na produção, comandado pelo rendimento. Essa dinâmica revela a importância do uso da tecnologia na ocupação do $\mathrm{CN}$, que instala um novo padrão produtivo intensivo em capitais, em contraposição ao tradicional, baseado principalmente no uso da terra "natural" e trabalho. Observa-se, portanto, que a "nova" ocupação dos CN envolveu, na primeira fase, dois processos bem claros: de um lado, a substituição parcial de culturas já presentes, como a cana de açúcar, mandioca e arroz, por novos produtos, em particular a soja e o milho, e de outro, a introdução de novas práticas de cultivo, mais intensivas em capital e com nível de rendimento por hectare mais elevado.

Os resultados indicam que a expansão da produção agrícola realmente ocorreu no segundo período (1999-2001 e 2010-2012). A quantidade produzida cresceu $112 \%$, saltando de 9,2 milhões de toneladas para 19,5 milhões, enquanto a nacional cresceu 101\% (IBGE, 2015c). Neste período, o aumento da produção no CN foi comandado pela intensificação da expansão da fronteira, impulsionada pela abertura de novas áreas para cultivo, mudança na composição do produto e pelos ganhos de produtividade, que se traduzem no efeito área (59\%), efeito rendimento $(31 \%)$ e estrutura produtiva (24\%). Já o efeito localização geográfica foi negativo $(-2,3 \%)$, reflexo da retração de outras culturas e/ou da redução na produtividade média em função da abertura de novas áreas agrícolas. As culturas que mais contribuíram para o aumento da produção foram (em toneladas): soja (3,9 milhões); cana-de-açúcar (3,4 milhões); milho (1,6 milhão) e algodão herbáceo (1,3 milhão), que representam $98 \%$ da variação total na produção.

Verifica-se que o efeito área prevaleceu na expansão da soja, variação de $484 \%$, seguido pelo efeito rendimento $(380 \%)$, revelando a característica da ocupação agrícola no $\mathrm{CN}$ e no período analisado: incorporação de novas áreas baseada na aplicação intensiva de tecnologia. Contudo, o efeito localização geográfica foi negativo $(-43,6 \%)$, resultado que pode ser considerado consistente com o processo de expansão da soja na região, que desde o início tem adotado os mesmos pacotes tecnológicos usados nas demais áreas do País, caracterizados pelo uso intensivo de capital (BUAINAIN et al., 2014). Assim, o rendimento 
acompanha os ganhos de produtividade associados à introdução de inovações. O efeito localização geográfica negativo pode ser explicado pela combinação da redução da dinâmica de ocupação da fronteira agrícola, que tende a ser positivo no primeiro momento, com o deslocamento da produção de áreas antigas para novas áreas com melhor potencial, e da própria expansão da fronteira que foi absorvendo áreas de menor potencial no início da ocupação. A expansão da cana-de-açúcar também foi comandada pelo efeito área $(46,4 \%)$, pelo efeito localização geográfica $(16 \%)$ e pelo efeito rendimento ( $9 \%$ ). No caso do milho, o efeito rendimento sustentou a expansão, variação de $161 \%$, seguido pelo efeito área (65\%) e pelo efeito localização geográfica $(57,5 \%)$. O elevado efeito rendimento no caso do milho se deve à substituição do cultivo "tradicional" pelo milho produzido em larga escala, com base na tecnologia utilizada pelos produtores de grãos nas áreas de Cerrado. Por fim, a variação do algodão herbáceo foi sustentada pelo efeito área $(648 \%)$, efeito localização geográfica ( $248 \%$ ) e efeito rendimento (133\%), mas também apoiada por novos sistemas de manejo mais intensivos em capital.
Em 2012, apenas três municípios, São Desidério e Formosa do Rio Preto na Bahia, e São Raimundo das Mangabeiras, no Maranhão, contribuíram com 23,5\% da produção das lavouras temporárias no $\mathrm{CN}$ (Figura 2), um total de 4,6 milhões de toneladas. Os 10 maiores municípios produtores responderam por $46 \%$ da produção do CN, 9 milhões de toneladas. No Mapa 2 é possível visualizar que a produção está concentrada na região noroeste da Bahia, divisa com os estados de Tocantins e Goiás, além de uma segunda área na divisa sul entre Piauí e Maranhão. A concentração evidencia o potencial para o crescimento da agricultura no $\mathrm{CN}$, com a expansão do mesmo padrão para outros municípios, repetindo o processo observado em Mato Grosso e Goiás.

Vale destacar que os municípios de São Desidério, Formosa do Rio Preto e São Raimundo das Mangabeiras também são aqueles que apresentaram o maior crescimento absoluto na quantidade produzida entre 1990-91-92 e 2010-11-12, representando $40,3 \%$ do aumento total registrado no CN (10,6 milhões de toneladas). A Figura 3 permite verificar que os municípios com as maiores variações absolutas na produção entre

Figura 2. Distribuição relativa da quantidade produzida das lavouras temporárias por município do Cerrado Nordestino: 2012

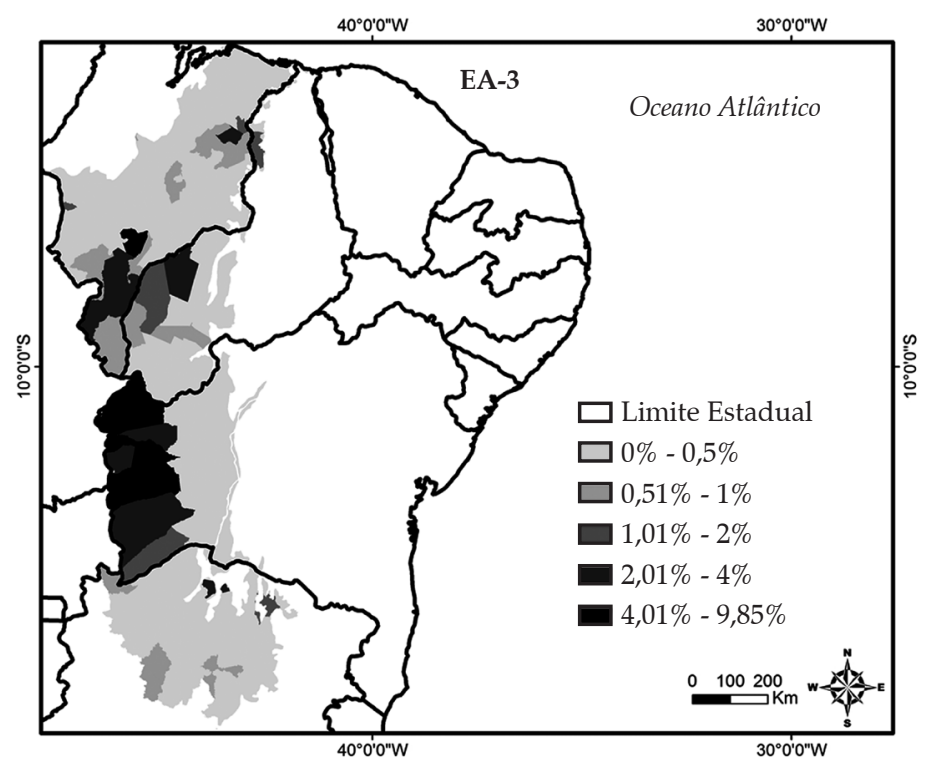

Fonte: Preparado pelos autores com base em IBGE (2015c). 
Figura 3. Variação Absoluta na Quantidade Produzida das Lavouras Temporárias por Município do Cerrado Nordestino (em toneladas): 2010-11-12/1990-91-92

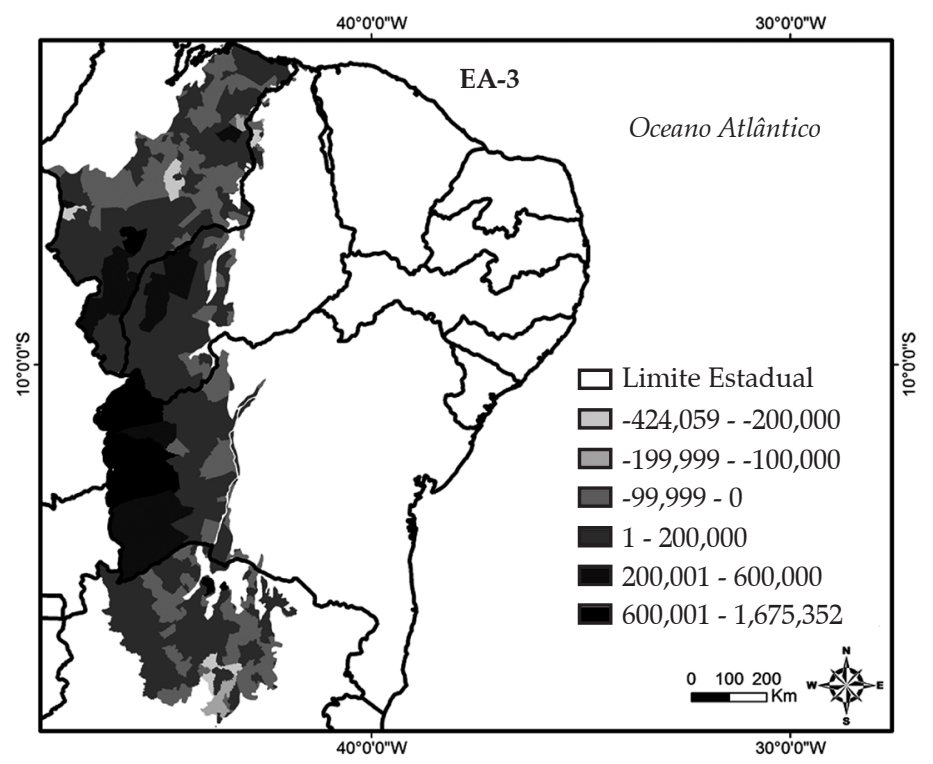

Fonte: Preparado pelos autores com base em IBGE (2015c).

1990-91-92 e 2010-11-12 estão localizados no noroeste da Bahia, divisa com Tocantins e Goiás, e na divisa sul de Piauí e Maranhão, a região conhecida como Matopiba, formada pelos estados do Maranhão, Tocantins, Piauí e Bahia (MAPA, 2013). Esse mapa revela a área mais dinâmica da região Nordeste, em termos da produção agrícola baseada em novas tecnologias.

Os resultados mostram que a ocupação agrícola do $\mathrm{CN}$ tem sido muito dinâmica, mas que esse processo está muito concentrado espacialmente. Esses resultados podem auxiliar na formulação de políticas públicas para estimular a difusão desse dinamismo para outros municípios, contribuindo para transformar esse impulso inicial em um processo de desenvolvimento regional, muito necessário para essa região (BUAINAIN e GARCIA, 2015).

\subsection{Análise do grau de contribuição}

A partir dos resultados do grau de contribuição de cada efeito (Figura 4) é possível observar que, entre 1990-91-92 e 1999-00-01, a expansão da produção no $\mathrm{CN}$, em especial no noroeste da Bahia, divisa com Tocantins e Goiás, e no sul do Maranhão, divisa com o Piauí, envolve - e reflete - os três efeitos, uma vez que os resultados indicam "baixo positivo".

No entanto, cabe fazer algumas observações. Por um lado, os resultados apresentados na Figura 4, indicam uma distribuição do efeito rendimento alto/baixo positivo em todo o território do $\mathrm{CN}$. Esse padrão pode ser atribuído ao intenso avanço tecnológico no manejo do solo, contribuindo para o aumento da produtividade geral das culturas agrícolas. Por outro, observa-se um grande número de municípios com efeito área baixo/alto negativo. Esse padrão indica que ocorreu uma perda/substituição de área cultivada, dinâmica associada à ocupação da fronteira agrícola.

Entre 1999-00-01 e 2010-11-12 a dinâmica de expansão da produção em toda a região apresenta importante contribuição do efeito área e do efeito rendimento, com exceção do norte de Minas Gerais. A grande mudança foi verificada no efeito estrutura produtiva, em que a região 
Figura 4. Decomposição das Fontes de Crescimento da Quantidade Produzida das Lavouras Temporárias por Município do Cerrado Nordestino: 2010-11-12/1990-91-92
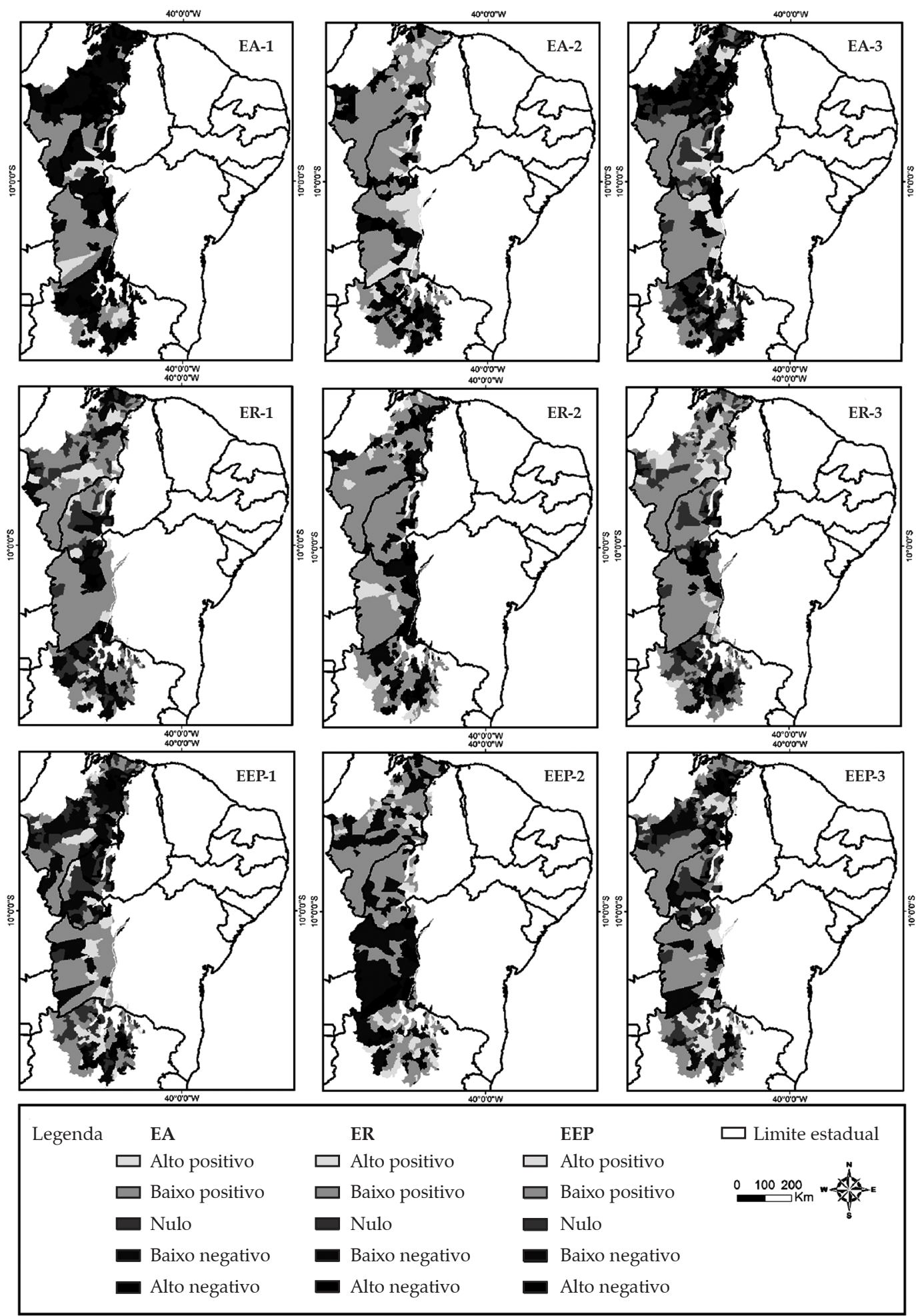

Nota: EA - Efeito Área; ER - Efeito Rendimento; EEP - Efeito Estrutura Produtiva. EA-1, ER-1 e EEP-1 - 1999-00-01/1990-91-92; EA-2, ER-2 e EEP-2 2010-11-12/1999-00-01; EA-3, ER-3 e EEP-3 - 2010-11-12/1990-91-92.

Fonte: Preparado pelos autores com base nos resultados da Análise Shift-share. 
noroeste da Bahia, divisa com Goiás e Tocantins, que era muito dinâmica, apresenta efeito baixo/ negativo, sinalizando que não houve grandes alterações no conjunto da produção, resultado do domínio do sistema soja-milho.

Por fim, analisando todo o período, entre 1990-91-92 e 2010-11-12, observa-se o predomínio do efeito rendimento baixo/alto positivo, com exceção novamente do norte de Minas Gerais. Todavia, os resultados também indicam que o efeito área e o efeito estrutura produtiva baixo/ alto positivo apresentaram importante contribuição nas regiões que abrigam o sistema soja-milho instalado recentemente no $\mathrm{CN}$. Na verdade, nessas regiões a dinâmica das lavouras temporárias foi comandada pelos três efeitos, revelando o dinamismo da nova estrutura produtiva instalada na região, similar àquela encontrada no Cerrado do Centro-Oeste.

\section{Considerações gerais}

O presente artigo analisou a dinâmica da produção agrícola nesta "nova" fronteira, o Cerrado - ou cerrados - Nordestino, utilizando a metodologia Shift-share para identificar as fontes de crescimento agrícola entre 1990 e 2012. A análise integrou os resultados da aplicação do modelo Shift-share adaptado para o setor agrícola às técnicas dispostas pelo Sistema de Informações Geográficas (SIG's), o que permitiu a espacialização dos resultados no CN. Essa integração contribui para a melhor visualização da dinâmica espacial de ocupação e uso das terras no $\mathrm{CN}$, e sem dúvida fornece subsídios mais adequados para a tomada de decisões dos agentes econômicos, em particular para a formulação de políticas públicas.

Os resultados mostram que existe uma profunda heterogeneidade na ocupação da fronteira agrícola, e também revelam que o processo de ocupação tem sido concentrado em determinados municípios do $\mathrm{CN}$. Os resultados indicam que a imagem difundida sobre o dinamismo dos $\mathrm{CN}$ não corresponde à realidade, que a expansão do agronegócio tem sido concentrada e que não parece suficiente para reduzir as desigualdades regionais históricas da região. $\mathrm{O}$ dinamismo determinado pelo mercado precisa ser apoiado e complementado por políticas de desenvolvimento regional voltadas para potencializar e espalhar os efeitos positivos da expansão da agricultura.

A análise mostrou expansão de 119\% na quantidade produzida de lavouras temporárias entre 1990-1992 e 2010-2012 no CN, fato que é valorizado quando se leva em conta que a região era até recentemente considerada inapta para a produção agrícola, especialmente para as lavouras temporárias, em função das restrições ecológicas, sociais e econômicas. $\mathrm{O}$ destaque neste processo tem sido a dinâmica do setor sucroenergético e do complexo Soja-Milho, segmentos que têm comandado o desempenho recente do agronegócio brasileiro. Esses resultados mostram que está ocorrendo um deslocamento espacial das atividades, cujo objetivo é reduzir custos de produção e de movimentação logística para comercialização no mercado externo, especialmente para a Ásia e Europa. No entanto, a infraestrutura logística instalada no $\mathrm{CN}$ ainda é relativamente precária e limita a competitividade da produção. Outro resultado interessante é que o produto que mais contribuiu para o desempenho positivo da agricultura no $\mathrm{CN}$ foi a cana-de-açúcar (produção de 6,2 milhões de toneladas, em 2012), ainda que no conjunto a produção do complexo Soja-Milho seja superior (soja, 6 milhões; milho, 3 milhões). A produção de mandioca (1,6 milhões) cresceu mais do que a produção de algodão herbáceo (1,4 milhões), indicando certa discrepância entre a imagem que se difundiu do $\mathrm{CN}$, muito mais associada ao algodão do que à cana-de-açúcar e à mandioca, para mencionar dois produtos tradicionais da agricultura nordestina.

Ao analisar a dinâmica agrícola entre 1990-92 e 1999-2001 e 1999-2001 e 2010-2012 foi possível verificar que a verdadeira expansão da produção de lavouras temporárias ocorreu praticamente no segundo período. Entre 1990-92 e 1999-2001, a expansão na produção das lavouras temporárias 
foi de apenas 3,4\%, aumento de 307 mil toneladas. Portanto, as mudanças ocorreram mais na composição da estrutura produtiva. Porém, entre 1999-2001 e 2010-12 a produção aumentou 112\%, indicando a consolidação do processo de ocupação em novas bases produtivas. Em relação aos efeitos que contribuíram para a expansão das lavouras temporárias, no primeiro período, o efeito área e o efeito localização geográfica foram negativos, registrando queda da ordem de $0,6 \%$ e $25 \%$, respectivamente. Pode-se afirmar que o crescimento da produção neste período deveu-se, na totalidade, ao efeito rendimento e ao efeito estrutura produtiva, ambos positivos, com aumento de $5 \%$ e $24 \%$, respectivamente. Isto significa que o deslocamento geográfico da produção e as mudanças na estrutura produtiva da agricultura da região do $\mathrm{CN}$, decorrente da introdução dos novos produtos, mais que compensaram a redução da área. Já no segundo período, a expansão da produção agrícola foi comandada pela ocupação da fronteira, impulsionada pela abertura de novas áreas de cultivo, pela mudança na composição do produto e pelos ganhos de produtividade, que se traduzem no efeito área (59\%), efeito rendimento (31\%) e estrutura produtiva (24\%). Por sua vez, o efeito localização geográfica foi negativo em $2,3 \%$, reflexo da retração de outras culturas e/ou da redução na produtividade média em função da abertura de novas áreas de cultivo.

Por fim, os resultados mostram que apenas três municípios do CN, São Desidério e Formosa do Rio Preto, na Bahia, e São Raimundo das Mangabeiras, no Maranhão, contribuíram com $23,5 \%$ da quantidade produzida pelas lavouras temporárias em 2012, ou seja, um indício de que a dinâmica de ocupação esteja concentrada. Ainda, a análise espacial permitiu verificar que os municípios com as maiores variações absolutas na quantidade produzida entre 1990-91-92 e 2010-1112 estão localizados no noroeste da Bahia, divisa com Tocantins e Goiás, e na divisa sul de Piauí e Maranhão, a região conhecida como Matopiba, formada pelos estados do Maranhão, Tocantins, Piauí e Bahia. Desse modo, a análise desenvol- vida neste estudo revela o mapa produtivo da nova fronteira agrícola brasileira; também revela a necessidade urgente de formulação de políticas que viabilizem a difusão regional do dinamismo desse setor para áreas que têm ficado à margem desse processo, a despeito do potencial de recursos naturais. Ainda que este estudo não tenha focado nos produtores do $\mathrm{CN}$, sabe-se que os produtos são claramente associados a perfis distintos de produtores, o que é suficiente para indicar que os pequenos agricultores familiares da região não estão inseridos no dinamismo gerado pela expansão do agronegócio nos CN.

\section{Referências}

ANDRADES, T. O. e GANIMI, R. N. Revolução verde e a apropriação capitalista. CES Revista, Juiz de Fora, v. 21, p. 43-56, 2007.

BARFF, R. A. e KNIGHT III, P. L. Dynamic shift-share analysis. Growth and Change, Spring/1988.

BASTOS, S. Q. de A. e GOMES, J. E. Dinâmica da agricultura no estado de Minas Gerais: análise estrutural-diferencial para o período 1994-2008. Ruris, v. 8, n. 2, set. 2011.

BITTENCOURT, G. M. e GOMES, M. F. M. Fontes de crescimento da produção de cana-de-açúcar no Sudeste e Centro-Oeste do Brasil. Revista Desenvolvimento Regional, v. 19, n. 2, maio/ago 2014, p. 182-201.

BNB. Perfil do Banco do Nordeste - municípios atendidos, 2015. Disponível em: <https://goo.gl/nD05pF> Acesso em: 10 jun. 2015.

BROWN, J. H. Shift and share projections of regional economic growth: an empirical test. Journal of Regional Science, v. 9, n. 1, 1969, p. 1-18.

. The stability of the regional-share component: reply. Journal of Regional Science, v. 11, n. 1, 1971, p. 113-114.

BUAINAIN, A. M. et al. (Orgs.). O mundo rural no Brasil do século 21: a formação de um novo padrão agrário e agrícola. 1. ed. Brasilia/DF: Embrapa Informação Tecnológica, 2014, v. 1.

. e GARCIA, J. R. Recent Development Patterns and Challenges of Brazilian Agriculture. In: SHOME, P. e SHARMA, P. (Org.). Emerging Economies Food and Energy Security, and Technology and Innovation. 1. ed. Springer India, 2015, v. 1, p. 41-66. 
. e GARCIA, J. R. Evolução recente do agronegócio no Cerrado Nordestino. Estudos Sociedade e Agricultura, UFRRJ, v. 23, p. 166-195, 2015.

CAMACHO, R. S. O agronegócio latifundiário versus a agricultura camponesa: a luta política e pedagógica do campesinato. XIX Encontro Nacional de Geografia Agrária, São Paulo, 2009, p. 1-34. Disponível em: < http://goo.gl/odKQMu >. Acesso em: 21 ago. 2015.

CANUTO, A. Agronegócio: a modernização conservadora que gera exclusão pela produtividade. Revista NERA, ano 7, n. 5, ago./dez. 2005.

CARVALHO, R. de A. et al. Avaliação do crescimento da agricultura amazônica. Belém, PA, Embrapa-Cpatu, Documentos 77, 1994.

CEPEA - Centro de Estudos Avançados em Economia Aplicada. PIB Agronegócio - BR, 2015. Disponível em: $<$ http://goo.gl/5b4xT7>. Acesso em: 20 jan. 2015.

CURTIS, W. C. Shift-share analysis as a technique in rural development research. American Journal of Agricultural Economics, v. 54, n. 2, maio 1972, p. 267-270.

DIAS, R. dos S., SOUZA, J. L. L. L. e SANTOS, R. L. Aplicação de metodologias integradas para análise de mudança de uso no município de Curaçá (Bahia) de 1990 a 2008. Anais XVI Simpósio Brasileiro de Sensoriamento Remoto - SBSR, Foz do Iguaçu, Paraná, Brasil, 13 a 18 de abril de 2013.

DUNN, E. S. Jr. A statistical and analytical technique for regional analysis. Papers and Proceedings of the Regional Science Association, v. 6, 1960, p. 97-112.

ESTEBAN-MARQUILLAS, J. M. Shift- and share analysis revisited. Regional and Urban Economics, v. 2, n. 3, 1972, p. 249-261.

FEIX, R. D. e ZANIN, V. Fontes de crescimento da agricultura no estado do Rio Grande do Sul entre 1990 e 2010. Ensaios FEE, Porto Alegre, v. 34, número especial, 2013.

FELIPE, F. I. e MAXIMIANO, M. L. Dinâmica da agricultura no estado de São Paulo entre 1990-2005: uma análise através do modelo "Shift-share". In: XLVI Congresso da Sociedade Brasileira de Economia, Administração e Sociologia Rural (Sober), Rio Branco, Acre, 20 a 23 de julho de 2008. Disponível em: <http:// www.sober.org.br/>. Acesso em: 20 jan. 2014.

RIZATO, M. R. e MAGGIAN, R. C. Dinâmica da agricultura brasileira entre 1991-2008: análise pelo modelo Diferencial-Estrutural. Anais do $48^{\circ}$ Congresso da Sociedade Brasileira de Economia, Administração e Sociologia Rural, 25 a 28 de julho de 2010, Campo Grande, Mato Grosso do Sul, 2010.
FORNAZIER,A.e VIEIRAFILHO,J.E. R. Heterogeneidade estrutural na produção agropecuária: uma comparação da produtividade total dos fatores no Brasil e nos Estados Unidos. Texto para Discussão 1819, IPEA, 2013.

GASQUES, J. G. et al. Desempenho e crescimento do agronegócio no Brasil. Texto para discussão no 1.009, Instituto de Pesquisa Econômica e Aplicada (Ipea), 2004. Disponível em: <http://desafios2.ipea.gov.br/ pub/td/2004/td_1009.pdf>. Acesso em: 15 fev. 2010.

. et al. Projeções do agronegócio mundial e do Brasil. Ministério da Agricultura, Pecuária e Abastecimento (MAPA), Assessoria de Gestão Estratégica (AGE), 2007. Disponível em: <www.sober.org.br/palestra/6/1127. pdf>. Acesso em: 18 fev. 2010.

. et al. Produtividade e crescimento da agricultura brasileira. Brasília: MAPA. Nota técnica da Coordenação Geral de Planejamento Estratégico, 2011.

GRAZIANO DA SILVA, J. A nova dinâmica da agricultura brasileira. Campinas: Unicamp, 1996.

. O novo rural brasileiro. Coleção Pesquisas, v. 1, Instituto de Economia da Unicamp, $2^{\mathrm{a}}$ edição revisada, 1ำ reimpressão, Campinas, São Paulo, 2002.

HERATH, J., GEBREMEDHIN, T. G. e MAUMBE, B. M. A dynamic shift-share analysis of economic growth in West Virginia. Journal of Rural and Community Development, v. 6, n. 2, 2011, p. 155-169.

HERZOG, H. W. e OLSEN, R. J. Shift-share analysis revisited: the allocation effect and the stability of regional structure. Journal of Regional Science, v. 17, n. 3, 1977, p. 441-454.

HOMMA, A. K. O. Fontes de crescimento da agricultura Paraense - 1970-80. Belém: Embrapa-Cpatu, 1981.

IBGE. Geociências, 2015a. Disponível em: < http://goo. gl/NBa7Wq > . Acesso em: 10/06/2015.

. Sistema IBGE de Recuperação Automática - Sidra: Demográfico e Contagem, 2015b. Disponível em: <http://goo.gl/aeK6vz>. Acesso em: 10 jun. 2015.

. Sistema IBGE de Recuperação Automática - Sidra: Pesquisa Agrícola Municipal, 2015c. Disponível em: <http://goo.gl/aeK6vz>. Acesso em: 10 jun. 2015.

Sistema IBGE de Recuperação Automática Sidra: Produto Interno Bruto dos Municípios, 2015d. Disponível em: <http://goo.gl/aeK6vz> . Acesso em: 10 jun. 2015.

IGREJA, A. C. M. et al. Análise quantitativa do desempenho da agricultura paulista, 1966-77. Relatório de Pesquisa 7/82, Secretaria de Agricultura 
e Abastecimento, Governo do Estado de São Paulo, Instituto de Economia Agrícola, São Paulo, 1982.

KAGEYAMA,A.(Coord.). Onovo padrãoagrícolabrasileiro: do complexo rural aos complexos agroindustriais. Campinas, 1987. 121 p. (mimeografado).

LIMA, J. F. de et al. O uso das terras no sul do Brasil: uma análise a partir de indicadores de localização. Revista de Economia e Sociologia Rural, v. 44, n. 4, out./ dez. 2006.

LOPES, A. S. Solos sob "cerrados": Características, propriedades e manejo. 2. ed. Piracicaba: Associação Brasileira para pesquisa da Potassa e do Fosfato, 1984. $162 \mathrm{p}$.

MAPA - Ministério da Agricultura, Pecuária e Abastecimento. Projeções do agronegócio: Brasil 2012/2013 a 2022/2023, 2013. Disponível em: <www.agricultura. gov.br>. Acesso em: 27 jun. 2015.

. Acesso à informação, Estatísticas, Comércio exterior, Balança comercial, 2015. Disponível em: < http://goo.gl/ dGxIep >. Acesso em: 20 jan. 2015.

MIRANDA, R. S. e GOMES, R. A. Dinâmicas agrárias e conflitos socioambientais no Sul do Maranhão. In: Congresso Internacional das Alas, 28, 2011, Recife. Anais... Recife: Ed. da UFPE, 2011.

MUELLER, C. C. Políticas governamentais e expansão recente da agropecuária no Centro-Oeste. Planejamento e políticas públicas, Brasília, DF, n. 3, p. 45-73, jun. 1990.

MULLER, G. Complexo industrial e modernização agrária. São Paulo: HUCITEC, 1989.

PADRÃO, G. A., GOMES, M. F. M. e GARCIA, J. C. Determinantes estruturais do crescimento da produção brasileira de grãos por estados da federação: 1989/90/91 e 2006/07/08. Revista Econômica do Nordeste, v. 43, n. 1, jan./mar. 2012, p. 51-66.

ROMEIRO, A. R. O agronegócio será ecológico. In: BUAINAIN, A. M. et al. (Orgs.). O mundo rural no Brasil do século 21: a formação de um novo padrão agrário e agrícola. 1. ed. Brasilia/DF: Embrapa Informação Tecnológica, 2014, v. 1, p. 509-530.

ROSS, J. e SANCHES, L. (Orgs.). Geografia do Brasil. 4. ed. São Paulo: Edusp, 2001.

SANTOS, C. V. e ARAÚJO, M. da P. Três décadas de mudanças na composição da produção agrícola paranaense: uma análise quantitativa do desempenho das principais culturas de 1980 a 2010. Revista de Desenvolvimento Econômico, ano XVI, n. 29, dez. 2014.
SCHEER, M. A. P. da S. e ROCHA, J. V. Desempenho da produção agrícolas nos municípios do Comitê da Bacia Hidrográfica do Rio Mogi-guaçu, Estado de São Paulo, Período 1979 a 2001. Agricultura São Paulo, v. 52, n. 2, jul./dez. 2005, p. 47-58.

SENF, D. R. Shift-share analysis of rural retail trade patterns. Regional Science Perspectives, v. 18, n. 2, 1988, p. 29-43.

SILVA DIAS, G. L. e AMARAL, C. M. Mudanças estruturais na agricultura brasileira: 1980-1998. Serie Desarrollo Productivo, no 99, Cepal/ONU, Santiago de Chile, enero de 2001.

SILVA, R. G. da C. Amazônia globalizada: da fronteira agrícola ao território do agronegócio - o exemplo de Rondônia. Confins, n. 23, 2015.

SOUZA, R. da S. e WANDER, A. E. Aspectos econômicos da produção de feijão no Brasil. Revista de Política Agrícola, Brasília-DF, v. 23, n. 3, jul./ago. 2014.

SUASSUNA, J. A salinidade de águas do Nordeste SemiÁrido. Disponível em: <www.fundaj.gov.br>. Acesso em: 14 jul. 2013.

TEIXEIRA, J. C. Modernização da agricultura no Brasil: impactos econômicos, sociais e ambientais. Revista Eletrônica da Associação dos Geográfos Brasileiros, v. 2, n. 2, ano 2, set. 2005 .

TEIXEIRA, S. M. e MENDES, H. C. Composição da agricultura em microrregiões homogêneas de Goiás, análise de índices Shift-share, 1990-2009. Conjuntura Econômica Goiana, n. 24, mar. 2013.

VEIGA, J. E. da. A dimensão rural do Brasil. Estudos Sociedade e Agricultura, v. 12, n. 1, Rio de Janeiro, 2004, p. 71-94.

VIDAL, M. de F. e EVANGELISTA, F. R. Irrigação na área de atuação do Banco do Nordeste do Brasil, 2012. Disponível em: <www.senado.gov.br>. Acesso em: 5 jul. 2015.

VIEIRA JR., P. A. e VIEIRA, A. C. P. e BUAINAIN, A. M. O Centro-Oeste brasileiro como fronteira agrícola. In: Congreso de la Asociación Latino Americana de Sociología Rural, 7., 2006, Quito, Equador. Anais... Buenos Aires: Alasru, 2006.

YOKOYAMA, L. P., IGREJA, A. C. M. e NEVES, E. M. Modelo "shift-share": uma readaptação metodológica e uma aplicação para o estado de Goiás. Boletim Técnico do Instituto de Economia Agrícola, Agricultura em São Paulo, v. 37, n. 3, 1990, p. 19-29. 
Os modelos matemáticos usados na análise foram adaptados a partir dos estudos de Igreja et al. (1982) e Scheer e Rocha (2005) e Felipe e Maximiano (2008).

A variação total na quantidade produzida intertemporal pode ser calculada a partir da seguinte expressão:

$Q_{j t}-Q_{j 0}=\left(Q_{j t}^{A P}-Q_{j 0}\right)+\left(Q_{j t}^{R}-Q_{j t}^{A P}\right)+\left(Q_{j t}-Q_{j t}^{R}\right)$

$Q$ é a quantidade produzida $(Q)$, a cultura $j$, o tempo $t$, município $i, A P$ área plantada e $R$, a produtividade.

Em que:

$$
\begin{aligned}
& Q_{j t}^{A P}=\sum_{i=1}^{n}\left(\alpha_{i j 0} \times A P_{i t} \times R_{i j 0}\right) \\
& Q_{j t}^{R}=\sum_{i=1}^{n}\left(\alpha_{i j 0} \times A P_{j t} \times R_{i j t}\right)
\end{aligned}
$$

O coeficiente $\alpha$ representa a estrutura de cultivo do município $i$ da cultura $j$ no período $t$ em relação à área plantada com o cultivo $j$ no $\mathrm{CN}$ no período $t$ :

$$
\alpha_{i j t}=\frac{A P_{j i t}}{A P_{j t}}
$$

As diferenças do segundo membro da equação (1) revelam os efeitos isolados por tipo de lavoura temporária; portanto, tem-se que as equações:

$$
\begin{aligned}
& \Delta Q_{j}=Q_{j t}-Q_{j 0} \\
& E A=Q_{j t}^{A P}-Q_{j 0} \\
& E R=Q_{j t}^{R}-Q_{j t}^{A P} \\
& E L G=Q_{j t}-Q_{j t}^{R}
\end{aligned}
$$

Outra avaliação que é realizada refere-se à variação da quantidade produzida por município para o conjunto das lavouras temporárias, mas não permite identificar o efeito localização geográfica (ELG), porque este efeito é nulo.

A variação total na quantidade produzida municipal pode ser obtida como segue:

$$
Q_{i t}-Q_{i 0}=\left(Q_{i t}^{A P}-Q_{i 0}\right)+\left(Q_{i t}^{R}-Q_{i t}^{A P}\right)+\left(Q_{i t}-Q_{i t}^{R}\right)
$$

Considerando:

$$
\begin{aligned}
& Q_{i t}^{A P}=\sum_{j=1}^{k}\left(\beta_{i j 0} \times A P_{i t} \times R_{i j 0}\right) \\
& Q_{i t}^{R}=\sum_{j=1}^{k}\left(\beta_{i j 0} \times A P_{i t} \times R_{i j t}\right)
\end{aligned}
$$


O coeficiente $\beta$ corresponde à estrutura de produtiva do município $i$ no cultivo da lavoura $j$ no período $t$ em relação à área plantada total do município:

$$
\beta_{i j t}=\frac{A P_{j i t}}{A P_{i t}}
$$

As diferenças do segundo membro da equação (9) permite avaliar cada efeito isolado na variação total:

$$
\begin{aligned}
& \Delta Q_{i}=Q_{i t}-Q_{i 0} \\
& E A=Q_{i t}^{A P}-Q_{i 0} \\
& E R=Q_{i t}^{R}-Q_{i t}^{A P} \\
& E E P=Q_{i t}-Q_{i t}^{R}
\end{aligned}
$$

Por fim, avaliam-se os componentes de variação da $Q_{t}$ para o conjunto das lavouras temporárias desenvolvidas no $\mathrm{CN}$ :

$$
Q_{t} \sum_{i=1}^{n} \times \sum_{j=1}^{k}\left(\gamma_{i j 0} \times A P_{0} \times R_{i j t}\right)
$$

O coeficiente $\gamma$ indica parcela da área plantada total no $C N$ com a cultura $j$ no município $i$ no período $t$ :

$\gamma_{i j t}=\frac{A P_{j i t}}{A P_{t}}$

A variação total na quantidade produzida no $C N$ pode ser obtida pela:

$Q_{t}-Q_{0}=\left(Q_{t}^{A P}-Q_{0}\right)+\left(Q_{t}^{R}-Q_{t}^{A P}\right)+\left(Q_{t}^{E}-Q_{t}^{R}\right)+\left(Q_{t}-Q_{t}^{E}\right)$

Considerando:

$Q_{t}^{A P}=\sum_{i=1}^{n} \times \sum_{j=1}^{k}\left(\gamma_{i j 0} \times A P_{t} \times R_{i j 0}\right)$

$Q_{t}^{R}=\sum_{i=1}^{n} \times \sum_{j=1}^{k}\left(\gamma_{i j 0} \times A P_{t} \times R_{i j t}\right)$

$Q_{t}^{E}=\sum_{i=1}^{n} \times \sum_{j=1}^{k}\left(\beta_{i j 0} \times A P_{i t} \times R_{i j t}\right)$

O componente direito da equação (19) revela efeitos isolados da variação total:

$$
\begin{aligned}
& \Delta Q_{i}=Q_{i t}-Q_{i 0} \\
& E A=Q_{i t}^{A P}-Q_{i 0} \\
& E R=Q_{i t}^{R}-Q_{i t}^{A P} \\
& E E P=Q_{i t}-Q_{i t}^{R}
\end{aligned}
$$

